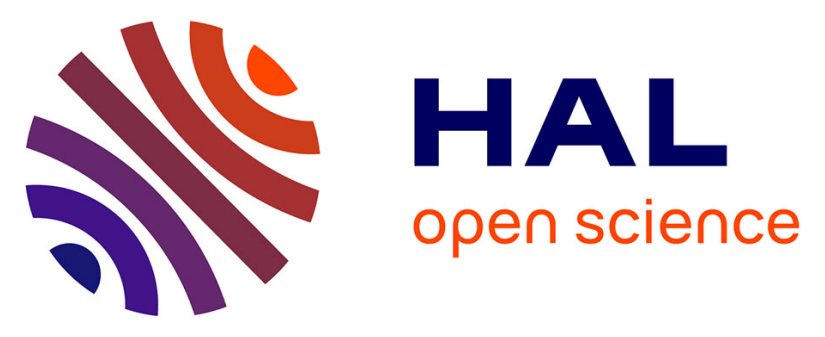

\title{
Yield enhancement strategy of dithiolopyrrolone from Saccharothrix algeriensis by aliphatic alcohols supplementation
}

\author{
Alaa Hamdar, Salomé El Hage, Fatima El Garah, Geneviève Baziard, \\ Christine Roques, Barbora Lajoie
}

\section{To cite this version:}

Alaa Hamdar, Salomé El Hage, Fatima El Garah, Geneviève Baziard, Christine Roques, et al.. Yield enhancement strategy of dithiolopyrrolone from Saccharothrix algeriensis by aliphatic alcohols supplementation. Process Biochemistry, 2019, 77, pp.18 - 22. 10.1016/j.procbio.2018.11.011 . hal-03485667

\section{HAL Id: hal-03485667 https://hal.science/hal-03485667}

Submitted on 20 Dec 2021

HAL is a multi-disciplinary open access archive for the deposit and dissemination of scientific research documents, whether they are published or not. The documents may come from teaching and research institutions in France or abroad, or from public or private research centers.
L'archive ouverte pluridisciplinaire HAL, est destinée au dépôt et à la diffusion de documents scientifiques de niveau recherche, publiés ou non, émanant des établissements d'enseignement et de recherche français ou étrangers, des laboratoires publics ou privés.

\section{(c)(1) $\$$}

Distributed under a Creative Commons Attribution - NonCommerciall 4.0 International 
Version of Record: https:/www.sciencedirect.com/science/article/pii/S1359511318308523

Manuscript_9078415c0f9cd680e8426ab623de74f7

1 Yields enhancement strategy of dithiolopyrrolone from Saccharothrix algeriensis by aliphatic alcohols

2 supplementation.

3 Alaa Hamdar ${ }^{\mathrm{a}}$, Salomé El Hage ${ }^{\mathrm{a}}$, Fatima El Garah ${ }^{\mathrm{a}}$, Geneviève Baziard ${ }^{\mathrm{a}}$, Christine Roques ${ }^{\mathrm{a}}$ and Barbora

$4 \quad$ Lajoie $^{\mathrm{a}^{*}}$

5 a Laboratoire de Génie Chimique, Université de Toulouse, CNRS, INPT, UPS, Faculté des Sciences

6 Pharmaceutiques, 35 chemin des Maraîchers, 31062 Toulouse Cedex 09, France

7 * Corresponding author: Barbora Lajoie: barbora.lajoie@univ-tlse3.fr

$8 \quad$ Telephone number: +33562256857

9 Fax number: +335622568 81 
11 The production of dithiolopyrrolones by Saccharothrix algeriensis was investigated after supplementing 12 the culture medium with ethanol and/or 1-butanol. Optimized Optimal conditions for the addition of 13 ethanol to the culture medium provided a maximal dithiolopyrrolone titer of about $200 \mathrm{mg} \cdot \mathrm{L}^{-1}$ after 5 days 14 of culture, roughly corresponding to a $600 \%$-increase. The involvement of ethanol in enzyme mediated reactive oxygen species generation, using diphenyleneiodonimm, NAD(P)H oxidase inhibitor, was observed. Using $\mathrm{NAD}(\mathrm{P}) \mathrm{H}$ oxidase inhibitor (diphenyleneiodonium) or reactive oxygen species

17 scavenger (para-aminobenzoic acid), we suppose that ethanol promotes the formation generation of reactive oxygen species in Saccharothrix algeriensis, which, in turn, act as elicitors for could induce biomass decline and dithiolopyrrolone overproduction. However, the underlying mechanisms remain to be elucidated. These results may be helpful for the eptimization control of dithiolopyrrolone yields from

21 Saccharothrix algeriensis cultures. and thus pave the way toward their large seale production.

23 Keywords

24 Saccharothrix algeriensis, dithiolopyrrolones, reactive oxygen species, alcohols addition 
27 In the search for substitutes to the current production processes of chemicals, microorganisms can be considered as an attractive alternative. Dithiolopyrrolones (DTP) are a promising class of antimicrobial agents found in the culture broths of some Streptomycetes, and other microorganisms such as the symbiotic bacteria, Xenorhabdus spp [1], or the marine bacterium Alteromonas rava [2]. This class of antibiotics encompasses about thirty compounds, including holomycin, thiolutin, aureothricin and thiomarinols, that are characterized by a unique pyrrolinodithiole $(4 H-[1,2]-$ dithiolo-[4, 3-b]-pyrrol-5one) nucleus substituted with two variable alkyl groups (Fig. 1) [3]. These compounds exhibited a broadspectrum antibacterial activity, especially against Gram-positive bacteria, mediated by RNA and protein synthesis inhibitions [4, 5]. Moreover, holomycin and thioluthin have been reported as potential antitumor agents $[6,7]$.

The antimicrobial activities of dithiolopyrrolones DTP can be of interest in the agro-forestry alimentary industry for managing of plant pathogens. For example, the DTP of the xenorhabdin group have shown potential in crop protection against plant diseases, such as the phytophthora blight or the grey mould [8]. DTP derivatives from Saccharothrix algeriensis could be used to control development of several strains of Fusarium oxysporum [9].

42 Thiolutin-like DTP are produced by various bacterial strains such as Saccharothrix algeriensis, a 43 filamentous actinobacterium isolated from the soil of the palm groves of Adrar in southern Algeria [9 10].

44 Several research groups have focused their attention on this bacterium because of its ability to produce new DTP from organic acids through precursor-directed biosynthesis [10-12-11-13]. However, few studies aimed at improving DTP production; therefore our objective is the development of new approaches to stimulate the production of secondary metabolites in S. algeriensis. In this study, we repert the role of two aliphatic aleohels, ethanol and 1 butanel, as inducers of DTP biosynthesis. In the natural environment, the microbial production of secondary metabolites is linked to many external factors and physiological signals. In liquid cultures, the production of secondary metabolites by Grampositive bacteria is generally confined to the stationary phase and is frequently associated with the depletion of nutrient pools. Thus, adding a chemical elicitor inducing stress conditions to the culture medium is a rather convenient strategy to enhance the synthesis of secondary metabolites [14]. Among many other chemicals, ethanol supplementation to the culture medium of some antibiotic-producing 
bacterial strains has a positive impact on antibiotic production. This phenomenon has been described for validamycin A production by Streptomyces hygroscopicus 5008 [13 15] өr jademycin B production by Streptemyees venezuelae ISP5230 [14]. The microbial secondary metabolism stimulation triggered by ethanol some alcohols may be mediated by ROS. Previous studies showed that one important generator of ROS were a family of membrane-bound enzymes, NAD(P)H oxidases (NOX) [15]. Moreover, it was recently proven that ethanol exposure increased NOX expression [16]. Besides their well-known toxicity toward living cells, ROS are also involved in complex physiological processes such as cell signaling [17 16] and could activate genes transcription of secondary metabolites biosynthesis [15].

Stress from aliphatic alcohols, like ethanol or 1-butanol, has been studied in various bacteria showing the ROS overproduction [17], but no reports were available about the use of 1-butanol for secondary metabolism elicitation. In this work, we focused on the effects of low concentration levels of two aliphatic alcohols (ethanol and 1-butanol) on cell growth and DTP biosynthesis in S. algeriensis.

The culture conditions were modified by adding those alcohols at different concentrations and at different times of incubation. In addition, Experiments were also conducted under conditions preventing the ROS overproduction (in presence of ROS scavenger or ROS producing enzyme inhibitor) [18] in order to demonstrate a putative link between ROS generation and DTP production in S. algeriensis. Diphenyleneiodinium (DPI) has frequently been used to inhibit reactive oxygen species ROS production mediated by flavoenzymes, particularly NAD $(\mathrm{P}) \mathrm{H}$ oxidase [18]. Para-aminobenzoic acid (PABA) is described as ROS scavenger [19].These results may be helpful for the control of secondary metabolism and optimization of DTP yields. obtained from $S$. algeriensis cultures and thus pave the way toward their large-scale production.

2. Materials and Methods

2.1 Microorganism and culture conditions

Saccharothrix algeriensis NRRL B-24137 (= DSM 44581) was used in this study. S. algeriensis was cultured on International Streptomyces Project 2 (ISP2) agar plates for 7 days at $30^{\circ} \mathrm{C}$, and the mycelium was then harvested, transferred into a cryoprotective medium $(0.1 \%$ Tween 80 and 1:1 (v/v) glycerolwater mixture) and stored at $-20^{\circ} \mathrm{C}$. The titer of the suspension expressed as colony-forming units per milliliter $\left(\mathrm{CFU} \cdot \mathrm{mL}^{-1}\right)$ of suspension was determined by enumeration on ISP2 agar plates. 
ISP2 solid medium contains (per liter of distilled water): $4 \mathrm{~g}$ yeast extract (Biomérieux), $4 \mathrm{~g}$ D-(+)glucose (Prolabo), $10 \mathrm{~g}$ malt extract (Bacto) and $18 \mathrm{~g}$ agar (Biomérieux). The $\mathrm{pH}$ of medium was adjusted to 7.0 with a $2 \mathrm{M} \mathrm{NaOH}$ solution, and the medium was autoclaved at $121^{\circ} \mathrm{C}$ for $20 \mathrm{~min}$.

For precultures and cultures, we used a basal semi-synthetic medium (SSM) [10] containing, per liter of distilled water: $2 \mathrm{~g}\left(\mathrm{NH}_{4}\right)_{2} \mathrm{SO}_{4}$ (Prolabo), $2 \mathrm{~g} \mathrm{NaCl}$ (Prolabo), $2 \mathrm{~g}$ yeast extract (Biomérieux), $5 \mathrm{~g} \mathrm{CaCO}$ (Prolabo), $1 \mathrm{~g} \mathrm{~K}_{2} \mathrm{HPO}_{4}$ (Fluka), $0.5 \mathrm{~g} \mathrm{KH}_{2} \mathrm{PO}_{4}$ (Fluka), $0.2 \mathrm{~g} \mathrm{MgSO} \cdot 7 \mathrm{H}_{2} \mathrm{O}$ (Prolabo), and $15 \mathrm{~g}$ of D-(+)-glucose (Prolabo). Before autoclaving, the $\mathrm{pH}$ of the medium was adjusted to 7.0 using $2 \mathrm{M} \mathrm{NaOH}$ solution.

Precultures of $S$. algeriensis were grown from $1 \mathrm{~mL}$ aliquots of frozen bacterial suspension $\left(10^{8} \mathrm{CFU} \cdot \mathrm{mL}^{-}\right.$ ${ }^{1}$ ) inoculated into $250 \mathrm{~mL}$ Erlenmeyer flasks containing $50 \mathrm{~mL}$ of $\mathrm{SSM}$ each. These precultures were incubated at $30^{\circ} \mathrm{C}$ under shaking at $250 \mathrm{rpm}$ for $48 \mathrm{~h}$. Thereafter, cultures were prepared in $250 \mathrm{~mL}$ Erlenmeyer flasks containing each $50 \mathrm{~mL}$ of culture medium inoculated with $5 \mathrm{~mL}$ of homogenized preculture. Cultures were incubated at $30^{\circ} \mathrm{C}$ under shaking at $250 \mathrm{rpm}$ for no longer than $120 \mathrm{~h}$ ( 5 days). The cultures were supplemented with either ethanol or 1-butanol (Acros) to achieve final concentrations ranging from $10 \mathrm{mM}$ to $680 \mathrm{mM}(0.06-4 \% \mathrm{v} / \mathrm{v})$ of ethanol, or $10 \mathrm{mM}$ to $100 \mathrm{mM}(0.09-0.9 \% \mathrm{v} / \mathrm{v})$ of 1-butanol. Alcohols were added to the medium at $0 \mathrm{~h}$, or $24 \mathrm{~h}$ or $48 \mathrm{~h}$ of incubation. In parallel, a nonsupplemented control culture was used for comparison under each experimental condition.

In our experiments, to evaluate the involvement of ethanol in ROS generation, two kinds of ROS inhibitors were used: DPI and PABA. Diphenyleneiodonium (DPI) has frequently been used to inhibit reactive oxygen species ROS production mediated by flavoenzymes, particularly NAD(P)H oxidase [18]. The culture medium was supplemented with 1 or $2 \mu \mathrm{M}$ of DPI (Sigma) or with 5 or $10 \mu \mathrm{M}$ of PABA (Acros) in absence or presence of ethanol $(300 \mathrm{mM}, 1.74 \% \mathrm{v} / \mathrm{v})$.

\subsection{Measurement of cell-growth and DTP production} For biomass measurement, the whole volume of culture broth was filtered using a vacuum filtration system. The obtained biomass was treated with $30 \mathrm{~mL}$ of $0.3 \mathrm{M} \mathrm{HCl}$ to remove $\mathrm{CaCO}_{3}$, the pellets thus collected were dried at $98^{\circ} \mathrm{C}$ for $24 \mathrm{~h}$ and weighed. The results were expressed as $\mathrm{g} \cdot \mathrm{L}^{-1}$ of culture broth. Culture supernatants were filtered through a $0.2 \mu \mathrm{m}$ filter and the analysis of DTP content was carried out by High Performance Liquid Chromatography (HPLC). Holothin was used as an external standard for the 
113 plotting of the calibration curve and the quantification of DTPs, since the molar extinction coefficient $(\varepsilon)$

114 of holothin at $390 \mathrm{~nm}$ is nearly identical to the extinction coefficient of all other known pyrrothines $\left(\varepsilon_{390}\right.$ ranging from 8317 to $9333 \mathrm{~L} \cdot \mathrm{mol}^{-1} \cdot \mathrm{cm}^{-1}$ ) [9]. The results were expressed as $\mathrm{mg} \cdot \mathrm{L}^{-1}$ of culture. The analytical HPLC equipment consisted of a Hitachi (La Chrom, Merck) instrument, equipped with an isocratic pump and UV detector. A Hypersil BDS C18 RP Column (Thermo Scientific) was used (250 $\mathrm{mm} \times 4.6 \mathrm{~mm}, 5 \mu \mathrm{m}$ particle size) fitted with a guard column (Thermo Scientific). The column was maintained at $30^{\circ} \mathrm{C}$ and the mobile phase consisted in a $3: 7(\mathrm{v} / \mathrm{v})$ distilled water/acetonitrile mixture; the flow rate was set to $0.8 \mathrm{~mL} \cdot \mathrm{min}^{-1}$. The injection volume was $20 \mu \mathrm{L}$. DTPs were detected at $390 \mathrm{~nm}$. were re-suspended in $1 \mathrm{~mL}$ of ethanol and sonicated for 10 minutes. After centrifugation, the resulting supernatant was analyzed by HPLC. No DTP signal was detected. Concentration (MBC) of ethanol and 1-butanol well plates using the Müller Hinton medium, in presence of serially diluted alcohols. The MIC of ethanol and 1-butanol against $S$. algeriensis were determined using the broth microdilution method described in the guidelines of the Clinical and Laboratory Standards Institute (CLSI) (CLSI. Methods for Dilution Antimicrobial Susceptibility Tests for Bacteria That Grow Aerobically; Approved Standard-Tenth Edition. CLSI document M07-A10. Wayne, PA: Clinical and Laboratory Standards Institute; 2015). Briefly, alcohols were loaded into the wells of a sterile 96-wells microtiter plate and subjected to two-fold serial dilutions with Müller Hinton medium (Biomerieux, Craponne, France) to achieve final concentrations of alcohols ranging from $64 \%$ to $1 \% \mathrm{v} / \mathrm{v}$.

The microtiter plates were inoculated with $S$. algeriensis preculture $\left(10^{6} \mathrm{CFU} \cdot \mathrm{mL}^{-1}\right)$, to obtain a final concentration of $10^{5} \mathrm{CFU} \cdot \mathrm{mL}^{-1}$. The 96 -well plates were incubated for 5 days at $30^{\circ} \mathrm{C}$. Cell suspensions were added into all wells except outer wells which were used as sterility control. Growth wells (with bacteria and without test solution) were also included. The plates were prepared in triplicate. 

determination experiment and then plating the aliquots onto ISP2 agar plates. MBC for each alcohol was

144 determined as the lowest alcohol concentration for which no bacterial growth could be observed in those subcultures after a 5 -day incubation at $30^{\circ} \mathrm{C}$. incubation on micro plates at $30^{\circ} \mathrm{C} . \mathrm{MBC}$ is the lowest dilution of alcohol that prevents the growth of sub-cultured $S$. algeriensis after 5 days incubation on the ISP2 plate at $30^{\circ} \mathrm{C}$.

\subsection{Statistical analysis}

All results are expressed as the mean values of three independent experiments carried out in triplicate. The error bars indicate the standard deviation (SD) from the mean value. Data were analyzed using Wilcoxon signed-rank test and Duncan's multiple comparison analysis on R Statistical Software Version 1.0.136 2009-2016 (C) RStudio, Inc. The difference between contrasting treatments was considered significant when $\mathrm{p}<0.05$.

3. Results and discussion

\subsection{Effect of non-cytotoxic ethanol concentrations on biomass and DTP production} First, the MIC and MBC of ethanol were determined, corresponding to $16 \%$ and $32 \% \mathrm{v} / \mathrm{v}$ respectively (equivalent to $2.74 \mathrm{M}$ and $5.48 \mathrm{M}$ ). Subsequent experiments were carried-out with sub-MIC concentrations of ethanol, ranging from 10 to $685 \mathrm{mM}$, added initially to the culture medium. The effect of ethanol concentrations on biomass and DTP production, after 5 days of incubation, are reported in Fig. 2a. The weight of biomass decreased significantly when ethanol concentration increased. When the ethanol concentration was $4 \% \mathrm{v} / \mathrm{v}(685 \mathrm{mM})$ the yield of biomass was decreased five-fold (to $0.30 \pm 0.07$ $\left.\mathrm{g} \cdot \mathrm{L}^{-1}\right)$, as compared to the non-supplemented control culture $\left(1.50 \pm 0.45 \mathrm{~g} \cdot \mathrm{L}^{-1}\right)$. There is also a dosedependent relationship between ethanol concentrations and DTP production, which rises from $31 \pm 7 \mathrm{mg} \cdot \mathrm{L}-$ ${ }^{1}$ of culture (control) to reach a maximum at $190 \pm 45231.2 \pm 32 \mathrm{mg} \cdot \mathrm{L}^{-1}$ of culture in the presence of $3 \% \mathrm{v} / \mathrm{v}$ of ethanol $(514 \mathrm{mM})$. At higher ethanol concentrations $(4 \% \mathrm{v} / \mathrm{v})$, the DTP production was further diminished, to $115 \pm 11 \mathrm{mg} \cdot \mathrm{L}^{-1}$ of culture, evidencing the negative impact of high ethanol concentration levels on DTP biosynthesis. 
171 Similar dose-dependent inductions of antibiotics in presence of ethanol under the appropriate conditions

172 were observed in cultures of other bacterial strains such as Streptomyces hygroscopicus 5008 өr 173 Streptomyces venezue ISP5230 [13-14] [15].

174

$175 \quad 3.2$ Effect of non-cytotoxic 1-butanol concentration levels on biomass and DTP production

176 The MIC / MBC were also determined: 4 and $8 \% \mathrm{v} / \mathrm{v}$, respectively, which correspond to $430 \mathrm{mM}$ and

$177870 \mathrm{mM}$ ). These values are much lower than the ones found with ethanol. In the subsequent experiences

178 S. algeriensis was incubated for 5 days in presence of 1-butanol at final concentrations of 10,50 and 100

$179 \mathrm{mM}$, which correspond to $0.09,0.45$ and $0.9 \% \mathrm{v} / \mathrm{v}$, respectively (Fig 2b).

180 At all concentrations tested, 1-butanol had a significantly negative impact on biomass production, yields

181 being about $30 \%$ lower than in control cultures. At $10 \mathrm{mM}$ and $50 \mathrm{mM}$ the DTP concentration remains

182 stable, at concentration level similar to that of the control (about $30 \mathrm{mg} \cdot \mathrm{L}^{-1}$ ) despite the biomass decline.

183 However, at $100 \mathrm{mM}$, DTP concentration drops dramatically to $4.4 \pm 0.4 \mathrm{mg} \cdot \mathrm{L}^{-1}$. These observations may

184 indicate that 1-butanol is more toxic to S. algeriensis than ethanol, resulting in a decline of metabolic

185 activity. As 1-butanol is more hydrophobic than ethanol, it may penetrate easily into the cytoplasmic

186 membranes and alter the membrane structure, interfering with vital functions of the bacterium [19 20].

187

\subsection{Effect of simultaneous addition of ethanol and 1-butanol on biomass and DTP production}

The simultaneous addition of $300 \mathrm{mM}$ of ethanol and $10 \mathrm{mM}$ or $50 \mathrm{mM}$ of 1-butanol to the culture medium at $0 \mathrm{~h}$ was tested for a potential synergistic effect of both alcohols on the DTP production (see

Fig. S1 in Supplementary data). After the simultaneous addition of both alcehols, the production of biomass was reduced, as compared with the control unexposed to any alcohol, but was similar to yield obtained from the culture supplemented with $300 \mathrm{mM}$ ethanol only (Fig. 3a). The DTP production increased slightly only in presence of $10 \mathrm{mM}$ of 1 - butanol with $300 \mathrm{mM}$ ethanol, as compared to the unsupplemented control (Fig. 3b). In conclusion, The combination of both alcohols entails no observable benefit in respect to of the production of DTP. These results highlight the detrimental effect of 1-butanol on $S$. algeriensis secondary metabolism. 

interrupted by two stationary phases related to the DTP biosynthesis [z 21]. The DTP production starts after the first growth period (i.e., after about $15 \mathrm{~h}$ of culture) when the first amino acid pools are depleted, and persists for approximately $20 \mathrm{~h}$. After $40 \mathrm{~h}$ of culture, the second growth phase takes place, and the second phase of DTP production coincides with the depletion of the glucose pool (after about $90 \mathrm{~h}$ of culture). Hence, in order to investigate the impact of ethanol on the different growth phases, the alcohol was added to the medium at $0 \mathrm{~h}$ (at the start of the first exponential phase), at $24 \mathrm{~h}$ (during the first phase of DTP biosynthesis) or at $48 \mathrm{~h}$ (at the early stage of the second exponential phase) after the beginning of culture fermentation.

For these experiments, a final ethanol concentration of $300 \mathrm{mM}$ was used. First, to assess if ethanol evaporated or was enzymatically catabolized during the incubation, ethanol concentration in culture broth was monitored at various time ( $0 \mathrm{~h}, 24 \mathrm{~h}, 48 \mathrm{~h}, 72 \mathrm{~h}, 96 \mathrm{~h}, 120 \mathrm{~h})$ of incubation, both in the presence and in the absence of S. algeriensis. In both experiments, the concentration of ethanol in the medium remained stable over 72 h, and decreased slightly afterward (see Fig S2 in supplementary data). After a $72 \mathrm{~h}$-incubation, the biomass production was significantly altered when ethanol was added at $0 \mathrm{~h}$ and $48 \mathrm{~h}\left(0.62 \pm 0.14 \mathrm{~g} \cdot \mathrm{L}^{-1}\right.$ and $0.90 \pm 0.10 \mathrm{~g} \cdot \mathrm{L}^{-1}$ respectively $)$ and slightly impacted when ethanol was added at $24 \mathrm{~h}\left(1.30 \pm 0.10 \mathrm{~g} \cdot \mathrm{L}^{-1}\right)$ as compared to the control $\left(1.50 \pm 0.30 \mathrm{~g} \cdot \mathrm{L}^{-1}\right)$ (Fig. 3a and $\left.4 \mathrm{~b}\right)$. Hence, ethanol addition seems to exert a significant positive effect on DTP production if is added at an early stage of culture (at $0 \mathrm{~h}$ ) (Fig. 3b). In this conditions, after $48 \mathrm{~h}$ of culture, the DTP concentration reached $37 \pm 7 \mathrm{mg} \cdot \mathrm{L}^{-1}$, more than twice the DTP concentration level observed in control $\left(14.5 \pm 2 \mathrm{mg} \cdot \mathrm{L}^{-1}\right)$, and peaked at $148 \pm 23 \mathrm{mg} \cdot \mathrm{L}^{-1}$ after $72 \mathrm{~h}$ of culture (Fig. $4 \mathrm{~b} 3 \mathrm{~b}$ ). However, the latest additions of ethanol ( $24 \mathrm{~h}$ or $48 \mathrm{~h}$ ) had no significant effect on DTP production after $72 \mathrm{~h}$ of incubation.

222 Consequently, if ethanol is added at an early stage of culture (at $0 \mathrm{~h}$ ) the first growth phase could be shortened and the metabolism could be shifted sooner toward the production of secondary metabolites, leading to enhancement of DTP biosynthesis. The addition of ethanol only after $24 \mathrm{~h}$ of culture, during the stationary phase, leads to a slight decrease in biomass yields and to a progressive increase in DTP production after $72 \mathrm{~h}$ of incubation as compared to the control (Fig. 4a and $4 \mathrm{~b} 3 \mathrm{a}$ and 3b). Thus, we hypothesize that the second growth phase may be either 
$48 \mathrm{~h}$ of culture, i.e. during the second growth phase, seems to have a deleterious effect on cells, as we observed decrease in biomass without positive effect on DTP production. The inhibition of cell growth and decrease of microbial viability, caused by low concentration levels of ethanol exposure, has already been described for Staphylococcus aureus [22]. A similar phenomenon has already been described for Staphylococcus atreus cultures exposed to low concentration levels of ethanol [21]. Ethanol inhibited cells growth and decreased the viability of the microorganisms. Moreover, this effect persisted long after ethanol in the culture medium had been.

These findings indicate that the cellular physiological state modifications in S. algeriensis, and DTP biosynthesis, seem to be closely related to the time of ethanol addition.

3.5 3.4Modulation of the inducing effect of ethanol by ROS inhibitors

241 Finally, we studied a putative mechanism involving ROS by which ethanol may stimulate DTP production. In order to establish whether ethanol promotes ROS production mediated by oxidases or peroxidases, experiments were conducted by combining ethanol with an inhibitor of key ROS-generating enzymes, DPI, which is widely used as an uncompetitive inhibitor of $\mathrm{NAD}(\mathrm{P}) \mathrm{H}$ oxidases [18].

245 We determined the concentrations of DPI which did not affect cell growth of S. algeriensis. DPI was added to the culture medium in final concentrations ranging from $1 \mu \mathrm{M}$ to $10 \mu \mathrm{M}$. After a 5-day incubation, no effect on either biomass production or DTP production could be observed for DPI concentrations $\leq 2 \mu \mathrm{M}$.

249 Then, 1 or $2 \mu \mathrm{M}$ of DPI were added to the culture medium at $0 \mathrm{~h}$, in the absence or presence of $300 \mathrm{mM}$ ethanol. As shown in Fig. 54 (a, b, white bars) in absence of ethanol, neither biomass nor DTP production were affected in cultures containing DPI. These parameters were similar to those of the control cultures. In accord with previous observations, the biomass yield was reduced by $60 \%$ in cultures supplemented with ethanol without ROS inhibitor, and the addition of DPI did not lead to almost complete biomass recovery (Fig. 5a4a grey bars). As we observed above, the presence of ethanol supports the microbial DTP production. But, the addition of the ROS inhibitor to culture containing ethanol canceled its positive effect on DTP production in dose-dependent manner, resulting in similar level of DTP in culture containing ethanol and $2 \mu \mathrm{M}$ of DPI as those observed in non-supplemented control 

enzymatic ROS production, induced by ethanol.

260 Supplementary experience was conducted in presence of ROS scavenger PABA. PABA, at 5 or $10 \mu \mathrm{M}$, was added to the culture medium at $0 \mathrm{~h}$, in the absence or presence of $300 \mathrm{mM}$ ethanol. No effect was observed on the biomass and DTP production in cultures containing PABA alone (Fig. $5 \mathrm{a}$ and b, white bars). In the cultures with PABA and ethanol, the biomass yield is more important than in the culture containing ethanol without this ROS scavenger, this yield is close to those of control culture without ethanol (Fig. 5a grey bars).

Presence of PABA in culture medium supplemented with ethanol reduces DTP concentration by about 60 grown could be related to PABA function as a protector of cells against ROS radicals [19]. In this way, PABA by reacting with ROS, the decline in DTP production might be due to the low level of ROS in culture medium.

Moreover, These results suggest several roles of ethanol in S. algeriensis culture: the deleterious effect on cell growth and elicitation of DTP biosynthesis, via ROS. These species have been shown to be toxic but also have role as signalling molecules to control microbial behavior, allowing for adaptation to stress injury [17][16].

\section{Conclusion}

277 This study revealed that sub-toxic concentrations of ethanol $(\leq 3 \% \mathrm{v} / \mathrm{v})$ could be beneficial to the DTP 278 production by S. algeriensis, in a dose-dependent relationship. Ethanol promotes the generation of ROS via NAD(P)H oxidases, and, as a result, microbial stress, leading to DTP overproduction. Further research should allow us to evaluate the impact of ethanol on the expression of genes implicated in DTP biosynthesis.

282

284 We thank Silvia Villarreal for the analysis of the ethanol content in culture broths through HPLCrefractive index detector. 
287 This research did not receive any specific grant from funding agencies in the public, commercial, or not-

288 for-profit sectors.

289 References

290 1. B.V. McInerney, R.P. Gregson, M.J. Lacey, R.J. Akhurst, G.R. Lyons, S.H. Rhodes, D.R. Smith, 291 L.M. Engelhardt, A.H. White, Biologically active metabolites from Xenorhabdus spp, Part 1. Dithiolopyrrolone derivatives with antibiotic activity, J. Nat. Prod. 54 (1991) 774-784.

2. H. Shiozawa, T. Kagasaki, T. Kinoshita, H. Haruyama, H. Domon, Y. Utsui, K. Kodama, S. Takahashi, Thiomarinol, a new hybrid antimicrobial antibiotic produced by a marine bacterium. Fermentation, isolation, structure, and antimicrobial activity, J. Antibiot. (Tokyo) 46 (1993) 1834-

3. W.D. Celmer, I.A. Solomons, The structures of thiolutin and aureothricin, antibiotics containing a unique pyrrolinonodithiole nucleus, J. Am. Chem. Soc. 77 (1955) 2861-2865. https://doi.org/10.1021/ja01615a058

4. B. Oliva, A. O’Neill, J.M. Wilson, P.J. O’Hanlon, I. Chopra, Antimicrobial properties and mode of action of the pyrrothine holomycin, Antimicrob. Agents Chemother. 45 (2009) 532-539. https://doi.org/10.1128/AAC.45.2.532-539.2001

5. A.N. Chan, A.L. Shiver, W.J. Wever, S.Z. Razvi, M.F. Traxler, B. Li, Role for dithiolopyrrolones in disrupting bacterial metal homeostasis, Proc. Natl. Acad. Sci. 114 (2017) 2717-2722. https://doi.org/10.1073/pnas.1612810114

6. B. Li, M.P. Lyle, G. Chen, J. Li, K. Hu, L. Tang, M.A. Alaoui-Jamali, J. Webster, Substituted 6amino-4H-[1,2]dithiolo[4,3-b]pyrrol-5-ones: synthesis, structure-activity relationships, and cytotoxic activity on selected human cancer cell lines, Bioorg. Med. Chem. 15 (2007) 4601-4608. https://doi.org/10.1016/j.bmc.2007.04.017

7. Y. Jia, S.L. Wu, J.S. Isenberg, S. Dai, J.M. Sipes, L. Field, B. Zeng, R.W. Bandle, L.A. Ridnour, D.A. Wink, R. Ramchandran, B.L. Karger, D.D. Roberts, Thiolutin inhibits endothelial cell adhesion by perturbing Hsp27 interactions with components of the actin and intermediate filament cytoskeleton, Cell stress \& chaperones 15 (2010) 165-81.

https://doi.org/10.1007/s12192-009-0130-0 
316 8. X.L. Fang, Z.Z. Li, Y.H. Wang, X. Zhang, In vitro and in vivo antimicrobial activity of 317 Xenorhabdus bovienii YL002 against Phytophthora capsici and Botrytis cinerea, J. Appl. Microbiol. 111 (2011) 145-154. https://doi.org/10.1111/j.1365-2672.2011.05033.x

9. R. Merrouche, A. Yekkour, L. Lamari, A. Zitouni, F. Mathieu, N., Efficiency of Saccharothrix algeriensis NRRL B-24137 and its produced antifungal Dithiolopyrrolones compounds to suppress Fusarium oxysporum-induced wilt disease occurring in some cultivated crops, Arab. J. Sci. Eng. 42 (2017) 2321-2327.

10. L. Lamari, A. Zitouni, H. Boudjella, B. Badji, N. Sabaou, A. Lebrihi, G. Lefebvre, E. Seguin, F.

11. N. Bouras, F. Mathieu, N. Sabaou, A. Lebrihi, Influence on dithiolopyrrolone antibiotic production

12. N. Bouras, R. Merrouche, L. Lamari, F. Mathieu, N. Sabaou, A. Lebrihi, Precursor-directed biosynthesis of new dithiopyrrolone analogs by Saccharothrix algeriensis NRRL B-24137, Process Biochem. 43 (2008) 1244-1252. https://doi.org/10.1016/j.procbio.2008.07.008

13. R. Merrouche, N. Bouras, Y. Coppel, F. Mathieu, N. Sabaou, New dithiolopyrrolone antibiotics induced by adding sorbic acid to the culture medium of Saccharothrix algeriensis NRRL B-24137, FEMS Microbiol. Lett. 318 (2011) 41-46. https://doi.org/10.1111/j.1574-6968.2011.02246.x

14. U. R.Abdelmohsen, T.Grkovic, S. Balasubramanian, M. S.Kamel, R. J.Quinn, U. Hentschel, Elicitation of secondary metabolism in actinomycetes, Biotechnology Advances, 33(6) (2015) 798811. https://doi.org/10.1016/j.biotechadv.2015.06.003 
15. W.W. Zhou, B. Ma, Y.J. Tang, J.J. Zhong, X. Zheng, Enhancement of validamycin A production by addition of ethanol in fermentation of Streptomyces hygroscopicus 5008, Bioresour. Technol. 114 (2012) 616-621. https://doi.org/10.1016/j.biortech.2012.03.124 D.L. Jakeman, C.L. Graham, W. Young, L.C. Vining, Culture conditions improving the production ef jadomycin B, J. Ind. Microbiol. Biotechnol. 3 (2006) 767-772.

https://doi.org/10.1016/j.freeradbiomed.2009.07.023

18. A. Liszkay, E. van der Zalm, P. Schopfer, Production of reactive oxygen intermediates $\left(\mathrm{O}_{2}{ }^{\cdot-}, \mathrm{H}_{2} \mathrm{O}_{2}\right.$, and $\mathrm{OH}$ ) by maize roots and their role in wall loosening and elongation growth, Plant Physiol. 136 (2004) 3114-3123. 
21. C. Strub, C. Brandam, X. Meyer, A. Lebrihi, Investigations of Saccharothrix algeriensis growth on synthetic media, J. Biosci. Bioeng. 106 (2008) 148-153. https://doi.org/10.1263/jbb.106.148

22. G.A. Chatterjee, G.A. Somerville, C. Heilmann, H.G. Sahl, H.H. Maurer, M. Herrmann, Very low ethanol concentrations affect the viability and growth recovery in post-stationary-phase Staphylococcus aureus populations, Appl. Environ. Microbiol. 72 (2006) 2627-2636.

Figures captions

Fig. 1

Structures of some dithiolopyrrolones

Fig. 2

Effect of ethanol (a) or 1-butanol (b) addition on S. algeriensis biomass (white bars) and DTP concentrations (grey bars) after 5 days of incubation. Results are expressed as means and standard deviations of triplicate experiments. Statistical differences $(*, \mathrm{p}<0.05, * *, \mathrm{p}<0.01$ and $* * *, \mathrm{p}<0.001)$ between test compound and its respective control $(n=9)$

392

Fig. 3

Comparison between effect of 1 - butanol alone (white bars) and a combination of 1 - butanol with $300 \mathrm{mM}$ ethanol (grey bars) on $S$. algeriensis (a) biomass and (b) DTP concentrations after 5 days of incubation. Results are expressed as means and standard deviations of triplicate experiments. Statistical differences $(*, \mathrm{p}<0.05, * *, \mathrm{p}<0.01$ and $* * *, \mathrm{p}<0.001)$ between test compound and its respective control $(\mathrm{n}=9)$

Fig. 4 Fig. 3

400

401

Effect of ethanol time addition on S. algeriensis (a) biomass and (b) DTP concentration after 3 days of 402 incubation. Ethanol final concentration $300 \mathrm{mM}(1.74 \% \mathrm{v} / \mathrm{v})$. Results are expressed as means and 
403 standard deviations of triplicate experiments. Statistical differences $(*, \mathrm{p}<0.05$, **, p<0.01 and ***,

$404 \mathrm{p}<0.001)$ between test compound and control $(n=9)$

405

406 Fig. 5 Fig. 4

407 Effect of ethanol alone (white bars) or in the presence of ROS-inhibitor (DPI) (grey bars) on

408 S. algeriensis (a) biomass and (b) DTP concentrations after 5 days of incubation. Results are expressed as 409 means and standard deviations of triplicate experiments. Statistical differences $(*, \mathrm{p}<0.05, * *, \mathrm{p}<0.01$ and $410 * * *, \mathrm{p}<0.001)$ between test compound and control, similar letters over the bars represent homogeneous 411 mean groups $(n=9)$

412

$413 \quad$ Fig. 5

414 Effect of ethanol alone (white bars) or in the presence of ROS scavenger (PABA) (grey bars) on 415 S. algeriensis (a) biomass and (b) DTP concentrations after 5 days of incubation. Results are expressed as 416 means and standard deviations of triplicate experiments. Statistical differences $(*, \mathrm{p}<0.05, * *, \mathrm{p}<0.01$ and $417 * * *, \mathrm{p}<0.001)$ between test compound and control, similar letters over the bars represent homogeneous 418 mean groups $(\mathrm{n}=9)$ 
421 Fig. 1

422<smiles>[R2]C(=O)Nc1c2sscc-2n([R1])c1=O</smiles>

R1: H R2: H Holothin

R1: $\mathrm{H} \quad \mathrm{R} 2: \mathrm{CH}_{3} \quad$ Holomycin

423

R1: $\mathrm{CH}_{3} \quad \mathrm{R} 2: \mathrm{CH}_{3} \quad$ Thiolutin

424

425 
Fig. 2

427
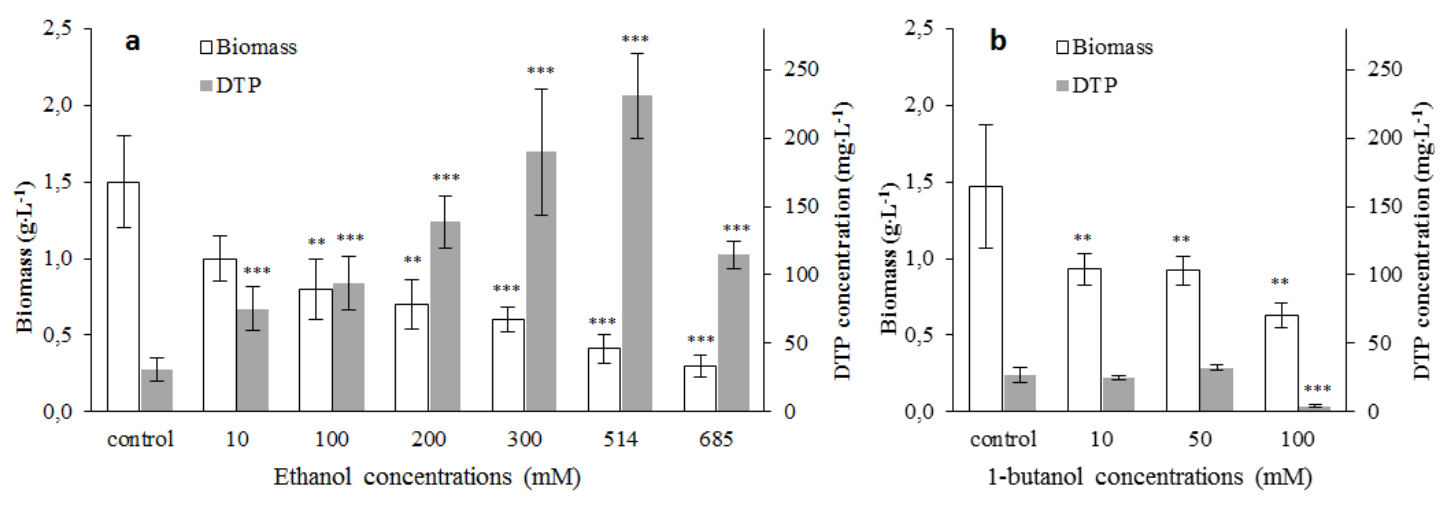
$431 \quad$ Fig. 3

432 Figure deleted:
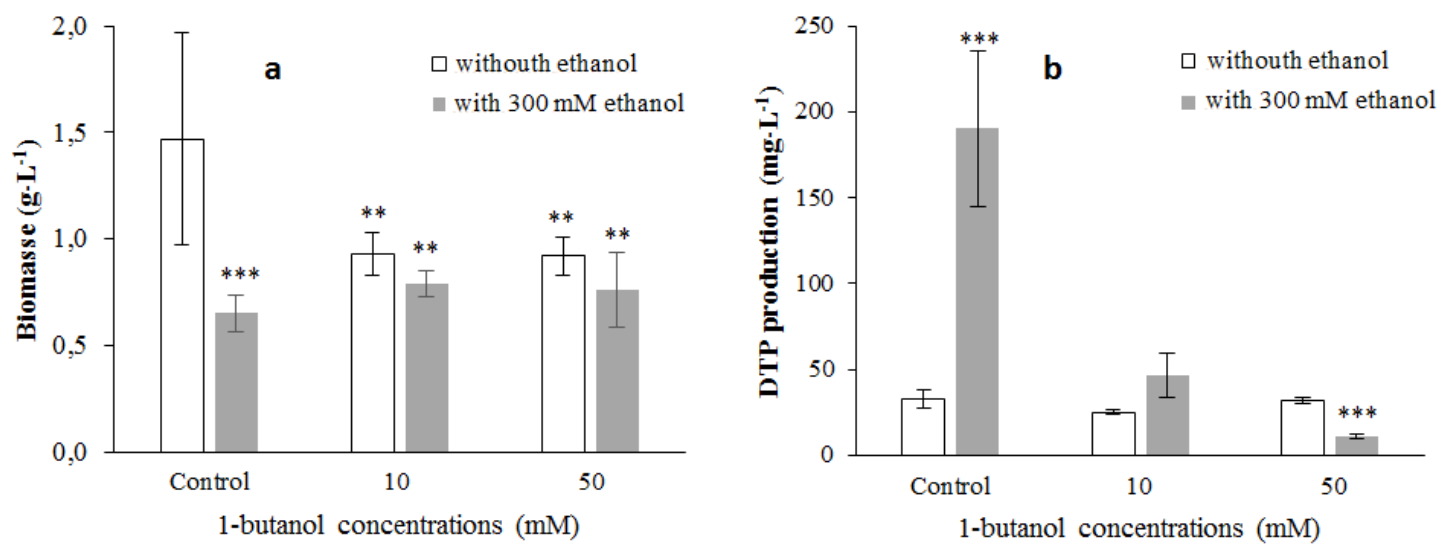

433

434

435 
Fig. 4 Fig. 3

437

438

439
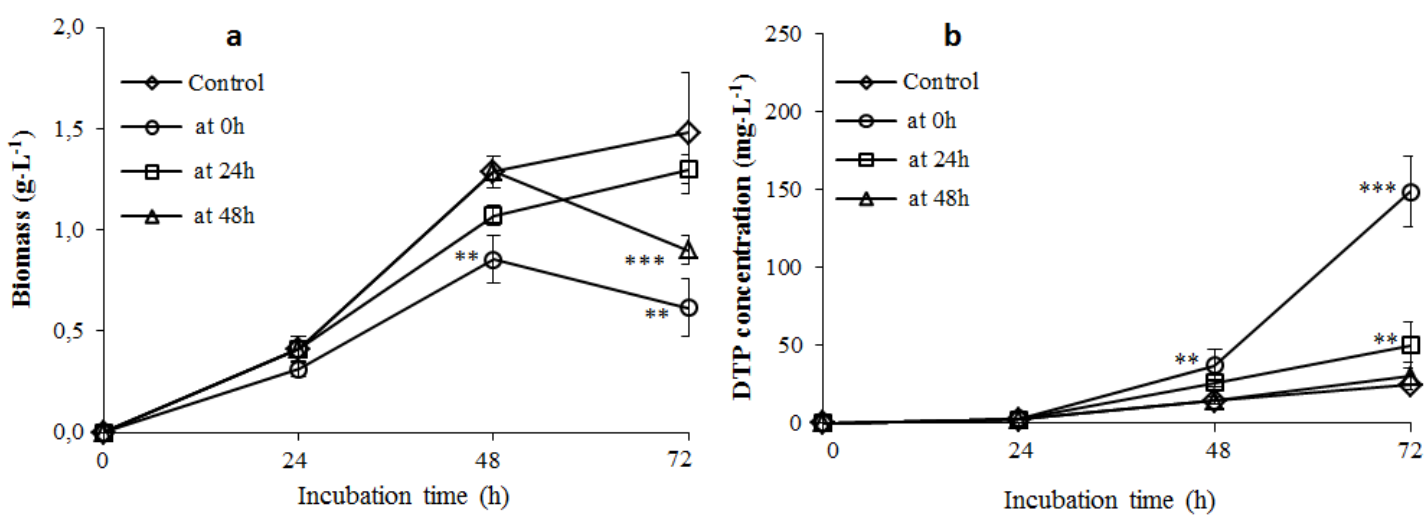

440

441 
Fig. 5 Fig. 4

443
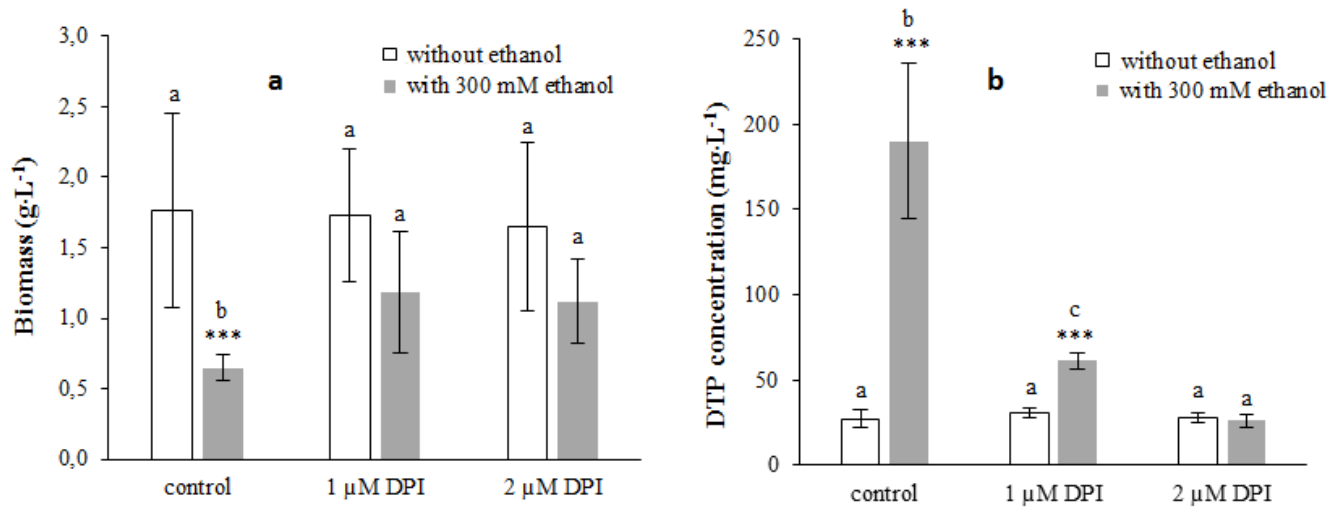

444

445

446 
Fig. 5

448

449
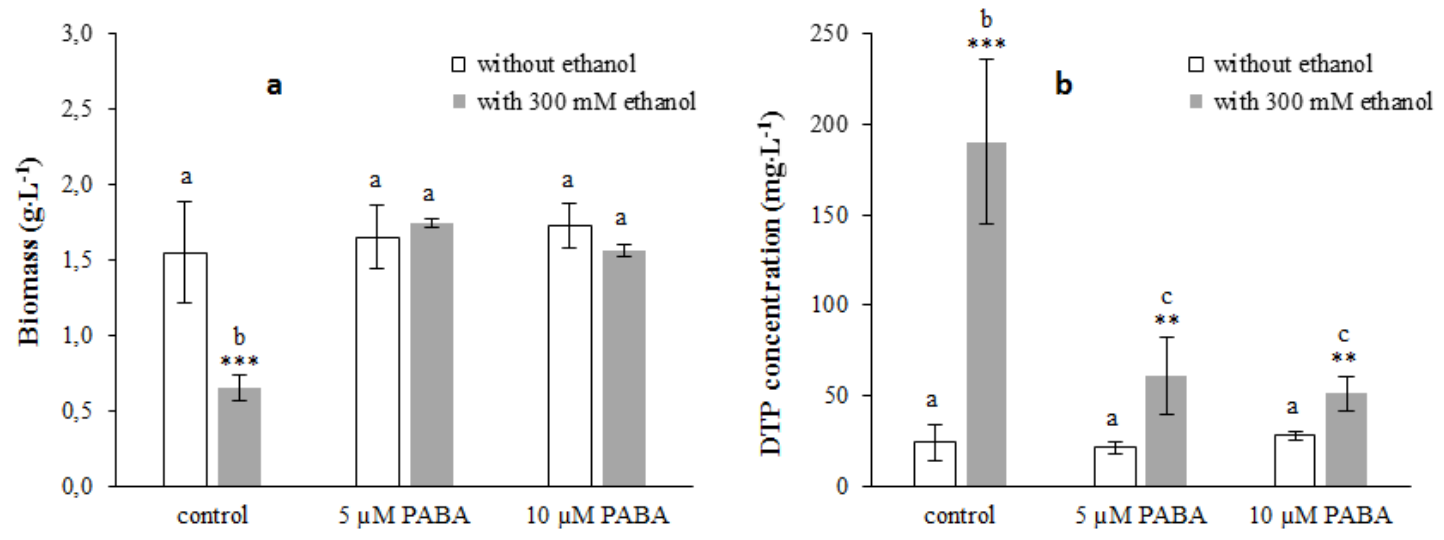

450

451 